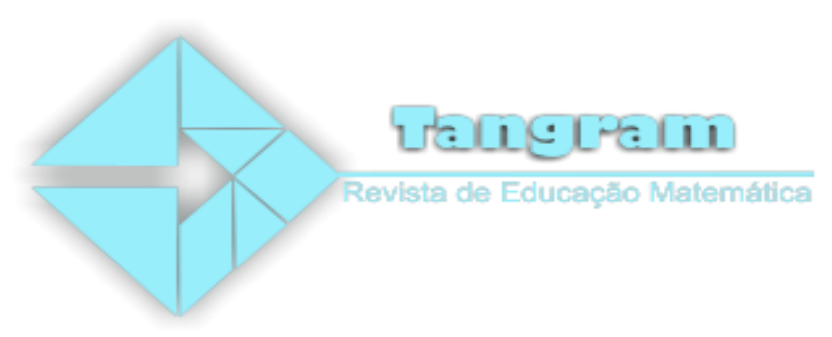

\title{
Economia doméstica e Educação Financeira na escola: diferenças a partir do gênero
}

\section{Domestic Economy and Financial Education in the school: differences from the gender}

\author{
Luzia de Fatima Barbosa Fernandes ${ }^{1}$ \\ Denise Silva Vilela ${ }^{2}$
}

\begin{abstract}
Resumo:Este artigo é parte de uma pesquisa de Doutorado em andamento cujo objeto central é a Educação Financeira na escola básica, e o norteamento da investigação é a proposta feita com a instituição da Estratégia Nacional de Educação Financeira. A análise dos dados, de cunho sociológico, baseou-se em diversos documentos alusivos à escola brasileira para então discutir como assuntos financeiros fizeram e fazem parte do currículo escolar. Metodologicamente, a pesquisa pautou-se em uma apreciação documental, incluindo leis, decretos e decretos-lei. Como resultado, o tratamento a respeito de finanças na escola, na disciplina de Economia Doméstica e na Educação Financeira, registrou distinções entre os conteúdos ministrados às meninas e aos meninos. Ademais, na atualidade, a Educação Financeira prima pela concordância aos preceitos do neoliberalismo, levando a escola a cumprir o papel de legitimar a doxa dominante.
\end{abstract}

Palavras-chave: Economia Doméstica; Educação Financeira; Escola Básica.

Abstract:This paper is part of an ongoing $\mathrm{PhD}$ research whose main subject is the Financial Education in the basic school, and the investigation is the proposal made with the institution of the National Strategy for Financial Education. The data analysis, supported on sociology, was based on several documents alluding to the Brazilian school and then discussed how financial themes were and are part of the school curriculum. Methodologically, the research was based on a documentary analyze, including laws, decrees and decrees-law. Findings, the treatment about finances in the school, in the Home Economics matter and in the Financial Education, recorded distinctions between the contents taught to the girls and the boys. In addition, at present, the Financial Education excels by the agreement to the neoliberalism precepts, conducing the school fulfill the role of legitimating the dominant doxa.

Keywords: Domestic Economy; Financial Education; Basic School.

${ }^{1}$ Doutoranda do Programa de Pós-graduação em Educação (PPGE) da UFSCar. E-mail: luziafbfernandes@gmail.com.

${ }^{2}$ Doutora em Educação Matemática pela Unicamp. Docente da Universidade Federal de São Carlos, membro permanente do Programa de Pós-graduação em Educação (PPGE) da UFSCar. E-mail: denisevilela@ ufscar.br.

Tangram - Revista de Educação Matemática, Dourados - MS - v.2 n.1, pp. 39 - 57 (2018) 


\section{Economia doméstica e educação financeira na escola: diferenças a partir do gênero}

\section{Introdução}

Este artigo provém da discussão levantada em uma pesquisa de Doutorado cujo objeto central é a Educação Financeira proposta para a sala de aula da escola básica por meio do material didático publicado pelo Comitê Nacional de Educação Financeira - Conef criado com a instituição no Brasil, em 2010, da Estratégia Nacional de Educação Financeira

- Enef. Limitamo-nos aqui a discutir aspectos dessa temática, mediante apresentação e análise de documentos concernentes à escola básica, focalizando as diferenças que há na relação entre o tema das finanças e os gêneros.

Vivemos em uma sociedade permeada pela proeminência capitalista das finanças e pelo ideário do neoliberalismo, conforme nos aponta Boltanski e Chiapello (2009). Nesse cenário, legitima-se o debate a respeito do tema da Educação Financeira na escola básica brasileira. Após a instituição da Enef (2010), observamos ações voltadas ao desenvolvimento dessas ideias e destinadas a diversos grupos da sociedade, em particular crianças e jovens da Educação Básica. Para expandir o trabalho com esse último público, avolumaram-se publicações de materiais didáticos dirigidos a todos os anos da escola básica, contemplando crianças de 6 a 17 anos.

Considerando a proposta, a partir da Enef, de que a questão das finanças venha a fazer parte do currículo da escola básica e reforçada pela indicação na Base Nacional Comum Curricular - BNCC - (Brasil, 2018), atentamo-nos aos currículos anteriores com a finalidade de encontrar vestígios do trabalho praticado nesse sentido em sala de aula.

Metodologicamente, o artigo inspira-se em uma análise documental de caráter histórico-bibliográfica, exercida por emparelhamento ou associação, estratégia que "consiste em analisar as informações a partir de um modelo teórico prévio" (Fiorentini \& Lorenzato, 2007, p.138) com base em pesquisas como a de Fernandes (2014). Destacamos os seguintes documentos: Lei de outubro de 1827; Decreto 7.247/1879; Decreto-Lei 4.244/1942; Decreto-Lei 8.347/1945; Decreto-Lei 8.529/1946; Decreto-Lei 8.530/1946 e Decreto 7.397/2010. Esse movimento de volta ao tempo, entendido por Bourdieu (2014) como "regressão", foi uma ação imposta pela própria "lógica da pesquisa" (p.43), com a finalidade de encontrar disciplinas escolares que tivessem nexo com o tema das finanças e entender as condições que levaram à inserção do tema no ambiente escolar em diferentes épocas e com diferentes propósitos. Percorrendo os documentos escolares, encontramos disciplinas

Tangram - Revista de Educação Matemática, Dourados - MS - v.2 n. 1, pp. 39 - 57 (2018) 


\section{Economia doméstica e educação financeira na escola: diferenças a partir do gênero}

correlatas à Educação Financeira, tal como a Economia Doméstica que, na sua especificidade, era voltada ao público feminino, tratando, dentre outros, de conteúdos ligados à administração das finanças do lar.

Nosso objetivo neste artigo é discutir sociologicamente como os diferentes assuntos das finanças foram propostos para sala de aula no Brasil desde as leis do Império e as primeiras leis instituídas na República. Destacaremos nesse debate as diferenças estabelecidas quanto ao gênero, assim configuradas: às meninas cabiam as finanças do lar e, aos meninos, uma educação voltada para o mundo externo, ou seja, ao mundo do trabalho, com o fim de acumulação de riquezas.

Para a análise projetada, valemo-nos de conhecimento em áreas como a da Sociologia, Sociologia da Educação, Sociologia Econômica, História da Educação e Educação Matemática. Em diálogo com esses campos intentamos um modo de ver sociologicamente a Educação Financeira indicada para a escola básica e suas implicações. Os estudos que abordam Sociologia e Educação Matemática têm sido conduzidos por pesquisadores do Grupo de Pesquisa Educação Matemáticos e Cultura do qual fazemos parte. Esses pesquisadores buscam desnaturalizar práticas do ensino de Matemática e da própria Matemática incorporando um novo modo de ver, tais como as pesquisas de Vilela e Souza Neto (2012) e Farias (2017). Na nossa proposta, portanto, discutiremos as diferenças no tratamento de assuntos financeiros na escola e sua relação com os gêneros e introduziremos a questão das doxas (Bourdieu, 1996) inculcadas pela escola em relação à sociedade.

O artigo está esquematizado da seguinte forma: a apresentação da temática será nesta introdução; na sequência, uma seção que abordará leis, decretos e decretos-leis que versam sobre a disciplina de Economia Doméstica na escola brasileira a partir do século XIX - com dados de autores da História da Educação e Sociologia -, destacando o papel da mulher influenciado pela educação recebida nas escolas; na seção seguinte serão expostas as imagens utilizadas na divulgação da Enef, na qual destacamos a permanência das diferenças entre os gêneros e a doxa imposta nas escolas; e, posteriormente, teceremos as considerações finais com a identificação da Educação Financeira com os preceitos do neoliberalismo.

\section{A disciplina de economia doméstica na escola básica do Brasil}

Tangram - Revista de Educação Matemática, Dourados - MS - v.2 n. 1, pp. 39 - 57 (2018) 


\section{Economia doméstica e educação financeira na escola: diferenças a partir do gênero}

Nesta seção faremos a exposição dos documentos encontrados na pesquisa pelo movimento de "regressão" (Bourdieu, 2014, p. 43) e, apoiando-nos em uma pesquisa histórico-bibliográfica, buscaremos os vestígios em disciplinas escolares de temas ligados às finanças a fim de entender as condições que redundaram na constituição do tema como disciplina escolar ou como um contexto a ser considerado em sala de aula.

Ao percorreremos as leis, decretos e decretos-lei instituídos em nível federal, tangentes à educação brasileira, deparamo-nos com uma disciplina presente nas escolas no século XIX e início do século XX, a saber, a Economia Doméstica. No modo como interpretamos, os assuntos então discorridos no âmbito dessa disciplina contemplavam algumas questões suscitadas atualmente pela Educação Financeira, tais como: orçamento doméstico, controle de gastos da família, decisões de compra, entre outros.

A seguir arrolamos os documentos selecionados nessa busca, em meio eletrônico, de leis sobre a escola brasileira, com descritores afins ao tema, tais como: finanças, orçamento, consumo, economia, Economia Doméstica e Educação Financeira.

Quadro 1: Leis, decretos e decretos-lei em que aparece mencionada a disciplina de Economia Doméstica

\begin{tabular}{|c|c|c|}
\hline $\begin{array}{l}\text { retos e } \\
\text { s-lei }\end{array}$ & Nível de ensino & Texto \\
\hline 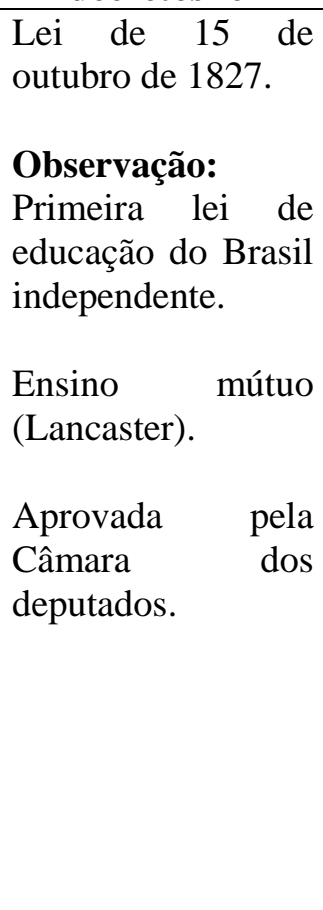 & $\begin{array}{l}\text { Criação de escolas } \\
\text { de primeiras letras } \\
\text { em todas as } \\
\text { cidades, vilas e } \\
\text { lugares } \\
\text { populosos mais } \\
\text { Império. }\end{array}$ & $\begin{array}{l}\text { Art } 6^{\circ} \text {. Os Professores ensinarão a ler, escrever as } \\
\text { quatro operações de arithmetica, pratica de quebrados, } \\
\text { decimaes e proporções, as nações mais geraes de } \\
\text { geometria pratica, a grammatica da lingua nacional, e os } \\
\text { principios de moral chritã e da doutrina da religião } \\
\text { catholica e apostolica romana, proporcionados á } \\
\text { comprehensão dos meninos; preferindo para as leituras } \\
\text { a Constituição do Imperio e a Historia do Brazil. } \\
\text { Art } 11^{\circ} \text {. Haverão escolas de meninas nas cidades e villas } \\
\text { mais populosas, em que os Presidentes em Conselho, } \\
\text { julgarem necessario este estabelecimento. } \\
\text { Art } 12^{\circ} \text {. As mestras, além do declarado no art } 6^{\circ} \text {, com } \\
\text { exclusão das noções de geometria e limitando a } \\
\text { instrucção da arithmetica só as suas quatro operações, } \\
\text { ensinarão tambem as prendas que servem á economia } \\
\text { domestica; e serão nomeadas pelos Presidentes em } \\
\text { Conselho, aquellas mulheres, que sendo brazileiras e de } \\
\text { reconhecida honestidade, se mostrarem com mais } \\
\text { conhecimentos nos exames feitos na fórma do art. } 7^{\circ} \text {. }\end{array}$ \\
\hline $\begin{array}{l}\text { Decreto } 7.247 \text { de } \\
19 \text { de abril de } 1879 .\end{array}$ & $\begin{array}{lr}\text { Reforma o ensino } \\
\text { primário } & \mathrm{e} \\
\text { secundário } & \text { no }\end{array}$ & $\begin{array}{l}\text { Art. } 4^{\circ} \mathrm{O} \text { ensino nas escolas primarias do } 1^{\circ} \text { gráo do } \\
\text { municipio da Côrte constará das seguintes disciplinas: } \\
\text { Nocõos de economia social (para os meninos). }\end{array}$ \\
\hline
\end{tabular}

Tangram - Revista de Educação Matemática, Dourados - MS - v.2 n. 1, pp. 39 - 57 (2018) 


\begin{tabular}{|c|c|c|}
\hline $\begin{array}{l}\text { Observação: } \\
\text { Ensino intuitivo } \\
\text { Reforma Leôncio } \\
\text { de Carvalho. }\end{array}$ & $\begin{array}{l}\text { município da } \\
\text { Côrte e o superior } \\
\text { em todo o } \\
\text { Império. }\end{array}$ & $\begin{array}{l}\text { Noções de economia domestica (para as meninas). } \\
\text { Art. } 9^{\circ} \text { O ensino nas Escolas Normaes do Estado } \\
\text { comprehenderá as disciplinas mencionadas nos dous } \\
\text { primeiros paragraphos seguintes: } \\
\text { Principios de economia politica. } \\
\text { Noções de economia domestica (para as alumnas). }\end{array}$ \\
\hline $\begin{array}{l}\text { Decreto-Lei } 4.244 \\
\text { de 9/04/1942. } \\
\text { Observação: } \\
\text { Governo Getúlio } \\
\text { Vargas. } \\
\text { Ministro Gustavo } \\
\text { Capanema }\end{array}$ & Secundário & $\begin{array}{l}\text { Do ensino secundário feminino } \\
\text { Art. 25. Serão observadas, no ensino secundário } \\
\text { feminino, as seguintes prescrições especiais: } \\
\text { Incluir-se-á, na terceira e na quarta série do curso } \\
\text { ginasial e em todas as séries dos cursos clássico e } \\
\text { científico, a disciplina de economia doméstica. } \\
\text { A orientação metodológica dos programas terá em mira } \\
\text { a natureza da personalidade feminina e bem assim a } \\
\text { missão da mulher dentro do lar. }\end{array}$ \\
\hline $\begin{array}{l}\text { Decreto-Lei } 8.347 \\
\text { de } 10 \text { de dezembro } \\
\text { de } 1945 . \\
\text { Observação: Dá } \\
\text { nova redação para o } \\
\text { Artigo } 25 \text { de } 1942\end{array}$ & Secundário & $\begin{array}{l}\text { Art. 25. Serão observadas, no ensino secundário } \\
\text { feminino, as seguintes prescrições especiais: } \\
\text { Incluir-se-á, na terceira e na quarta série do curso } \\
\text { ginasial, a disciplina de economia doméstica. } \\
\text { A orientação metodológica dos programas terá em mira } \\
\text { a natureza da personalidade feminina e bem assim a } \\
\text { missão da mulher no lar. }\end{array}$ \\
\hline \begin{tabular}{l} 
Decreto-Lei 8.529 \\
de 2 janeiro de \\
1946. \\
Observação: \\
Governo provisório \\
José Linhares \\
\multicolumn{4}{l}{ Ministério da } \\
Educação Raul \\
Leitão da Cunha
\end{tabular} & Primário & $\begin{array}{l}\text { Art. } 8^{\circ} \text { O curso primário complementar, de um ano, terá } \\
\text { os seguintes grupos de disciplinas e atividades } \\
\text { educativas: } \\
\text { I. Leitura e linguagem oral e escrita. } \\
\text { II, Aritmética e geometria, } \\
\text { III. Geografia e história do Brasil, e noções de geografia } \\
\text { geral e história da América; } \\
\text { IV. Ciências naturais e higiene. } \\
\text { V. Conhecimentos das atividades econômicas da } \\
\text { região. } \\
\text { VI. Desenho. } \\
\text { VII. Trabalhos manuais e práticas educativas referentes } \\
\text { às atividades econômicas da região. } \\
\text { VIII. Canto orfeônico. } \\
\text { IX. Educação física. } \\
\text { Parágrafo único. Os alunos do sexo feminino, } \\
\text { aprenderão, ainda, noções de economia doméstica e de } \\
\text { puericultura. } \\
\text { Art. } 9^{\circ} \text { O curso supletivo, para adolescentes e adultos, } \\
\text { terá dois anos de estudos, com as seguintes disciplinas: } \\
\text { I. Leitura e linguagem oral e escrita. } \\
\text { II. Aritmética e geometria. } \\
\text { III. Geografia e história do Brasil. } \\
\text { IV. Ciências naturais e higiene. } \\
\text { V. Noções de direito usual (legislação do trabalho, } \\
\text { obrigações da vida civil e militar). } \\
\text { VI. Desenho. } \\
\text { Parágrafo único. Os alunos do sexo feminino } \\
\text { aprenderão, ainda, economia doméstica e puericultura. }\end{array}$ \\
\hline
\end{tabular}

Tangram - Revista de Educação Matemática, Dourados - MS - v.2 n. 1, pp. 39 - 57 (2018) 


\begin{tabular}{|c|c|c|}
\hline $\begin{array}{l}\text { Decreto-Lei no } \\
8.530 \text { de } 2 \text { de } \\
\text { janeiro de } 1946 . \\
\text { Observação: } \\
\text { Governo } \\
\text { provisório: José } \\
\text { Linhares } \\
\text { Ministério da } \\
\text { Educação: Raul } \\
\text { Leitão da Cunha }\end{array}$ & Ensino Normal & $\begin{array}{l}\text { Art. } 7^{\circ} \text { O curso de regentes de ensino primário se fará } \\
\text { em quatro séries anuais, compreendendo, no mínimo, } \\
\text { as seguintes disciplinas: } \\
\text { Primeira série: 1) Português. 2) Matemática. 3) } \\
\text { Geografia geral. 4) Ciências naturais. 5) Desenho e } \\
\text { caligrafia. 6) Canto orfeônico. 7) Trabalhos manuais e } \\
\text { economia doméstica. 8) Educação física. } \\
\text { Segunda série: 1) Português. 2) Matemática. 3) } \\
\text { Geografia do Brasil. 4) Ciências naturais. 5) Desenho e } \\
\text { caligrafia. 6) Canto orfeônico. 7) Trabalhos manuais e } \\
\text { atividades econômicas da região. 8) Educação física. } \\
\text { Terceira série: 1) Português. 2) Matemática. 3) } \\
\text { História geral. 4) Noções de anatomia e fisiologia } \\
\text { humanas. 5) Desenho. 6) Canto orfeônico. 7) Trabalhos } \\
\text { manuais e atividades econômicas da região. 8) } \\
\text { Educação física, recreação e jogos. } \\
\text { Quarta série: 1) Português. 2) História do Brasil. 3) } \\
\text { Noções de Higiene. 4) Psicologia e pedagogia. 5. } \\
\text { Didática e prática de ensino. 6) Desenho. 7) Canto } \\
\text { orfeônico. 8) Educação física, recreação e jogos. } \\
\text { § } 1^{\circ} \text { O ensino de trabalhos manuais e das atividades } \\
\text { econômicas da região obedecerá a programas } \\
\text { específicos, que conduzam os alunos ao conhecimento } \\
\text { das técnicas regionais de produção e ao da organização } \\
\text { do trabalho na região. }\end{array}$ \\
\hline
\end{tabular}

Fonte: Disponível em: <http://www2.camara.leg.br>. Acesso em: 28 nov. 2017. (grifos nossos)

As leis, decretos e decretos-leis explicitados no quadro anterior nos apontam que, desde o século XIX até metade do século XX, o conteúdo de Economia Doméstica constava no currículo da escola básica brasileira e era destinado ao público feminino. Dentre os conteúdos trabalhados nessa disciplina, Serrano (1954) sublinha a necessidade da mulher a dona de casa - ter acesso a um "conjunto sistematizado de variados conhecimentos científicos", do qual destaca: "noções de higiene, nutrologia, contabilidade, puericultura, enfermagem, etc" (p. 15). No que diz respeito à contabilidade, Serrano (1954) enfatiza o orçamento doméstico no que tange às diversas despesas da família - separadas entre obrigatórias, necessárias e supérfluas -, e ainda interpreta o equilíbrio financeiro como condição para a harmonia da casa.

Objetivamente, como era uma disciplina oferecida às meninas, essa formação restringia a mulher a uma esfera privada, ou seja, limitava o seu papel na sociedade à criação de filhos, afazeres domésticos e administração do lar. Para as autoras Bastos e Garcia (1999), o século XIX notabilizou-se pela educação feminina voltada ao "âmbito privado" (p. 78). A disciplina de Economia Doméstica de que trata a Lei de 1827 incluía os conhecimentos

Tangram - Revista de Educação Matemática, Dourados - MS - v.2 n. 1, pp. 39 - 57 (2018) 


\section{Economia doméstica e educação financeira na escola: diferenças a partir do gênero}

"elementares de trabalhos de agulha - bordado e costura, e música", e, posteriormente, os assuntos relacionados à "cozinha, manutenção da roupa, cuidados com a limpeza da casa e do jardim, higiene" (Bastos e Garcia, 1999, p. 81).

Em 1879 é publicado o Decreto $n^{\circ}$ 7.247, que instituiu a reforma dos Ensinos Primário e Secundário. Esse decreto tinha dentre seus princípios a moral e a higiene. $\mathrm{O}$ higienismo ganha força no país nessa época (Segundo Império e Primeira República), momento em que a medicina vem a ser considerada "como um campo disciplinar autônomo" (Saviani, 2008, p. 137). O cenário brasileiro era marcado nessa época pelo processo de industrialização, e a educação cumpria um papel fundamental. Para Romanelli (1978), esse período, marcado pelas exigências da sociedade industrial, deixou o Estado como responsável pela educação. Com as mudanças no sistema de produção fazia-se necessário acabar com o analfabetismo da população. Segundo a autora,

o capitalismo, notadamente o capitalismo industrial, engendra a necessidade de fornecer conhecimentos a camadas cada vez mais numerosas, seja pelas exigências da própria produção, seja pelas necessidades do consumo que essa produção acarreta (Romanelli 1978, p. 59).

Com esse panorama capitalista industrial, fazia-se necessário que a população se qualificasse para poder participar e, na educação, essas ações eram representadas pelo desenvolvimento da leitura e da escrita, era o mínimo a ser feito para o acesso a esse sistema de produção e consumo.

O século XIX também se caracterizou pelo processo de urbanização e, com a reconfiguração desse mundo, a casa era o local por excelência das mulheres - "alçada à categoria de rainha do lar graças as positivistas e higienistas, deveria dedicar-se integralmente à família e aos cuidados domésticos" (Almeida, 2006, p. 182, grifos da autora). No final desse século, com a chegada da República, a mulher incorporou à sua imagem, "inspirada na filosofia comteana, a mulher-mãe com qualidades morais altruísticas, a fêmea humana, bondosa, redentora", e, nessa perspectiva, o argumento nacional da "domesticidade feminina" era disseminado no país, inclusive pelas próprias mulheres (Almeida, 2006, p. 182).

Esse perfil atribuído às mulheres vigorou até os anos iniciais do século $\mathrm{XX}$, nos quais a doutrina pregada pela Igreja Católica, respaldada na figura da virgem Maria, alentava ainda mais o mito da mulher-mãe, pura e reprodutora. Por isso que ideologias como o positivismo

Tangram - Revista de Educação Matemática, Dourados - MS - v.2 n. 1, pp. 39 - 57 (2018) 


\section{Economia doméstica e educação financeira na escola: diferenças a partir do gênero}

e o higienismo reservavam para a mulher o espaço doméstico, desse modo, "a educação positiva, assim como o catolicismo, fez dela um anjo de bondade, redentora da família e da pátria" (Almeida, 2006, p. 184). A educação, incidindo sobre as questões higiênicas, enquadrava a mulher nos padrões europeus, em que as atividades domésticas eram conduzidas segundo esses preceitos. Na ocasião, se a mulher se libertasse intelectualmente e disputasse espaço com os homens, isso representaria um risco à sociedade. Sua atuação deveria ater-se ao lar, cuidando, inclusive, do bem-estar dos homens. E, nesse momento sociocultural, a escola cumpria com o papel de instruir e reforçar esse papel.

O Decreto-Lei $n^{\circ} 4.244$ de abril de 1942, que trata da Lei Orgânica do Ensino Secundário (composto pelo curso ginasial - de quatro anos - e um segundo ciclo, pelos cursos clássico e científico - de três anos), explicitamente conduz os conteúdos para o público feminino com o intuito de manter a mulher em sua "missão", que deveria ser desempenhada no universo privado do lar. Esse Decreto-Lei 4.244 "refletia o momento político pelo qual passava a sociedade brasileira em pleno Estado Novo, vivendo, portanto, um regime autoritário e populista" (Romanelli, 1978, p. 159). As mesmas recomendações alusivas à inserção da disciplina de Economia Doméstica para o público feminino estão presentes no Decreto 8.529, de janeiro de 1946, referente ao ensino primário.

De modo análogo, o que era determinado aos Ensinos Primários e Secundários também era contemplado nos Cursos de formação para o magistério - Curso Normal conforme Decreto-lei 8.530, de janeiro de 1946, no qual a disciplina de Economia Doméstica fazia parte do currículo. Para além da economia na esfera privada do lar, o currículo trazia também as atividades econômicas da região como forma de interação com as condições de produção e trabalho regionais.

Quando se discutiu a atuação feminina além dos limites do lar, em que atuaria na educação escolarizada, o magistério tornou-se, para a mulher, o lugar perfeito para continuar com a missão, não contrariando valores como a domesticidade e maternidade do público feminino, embora essa formação para o magistério se estendesse também aos homens. Nas disciplinas de curso de formação de professores primários, podemos notar a existência de disciplinas ligadas ao lar.

Conforme Souza (2006), no Estado de São Paulo, nos primeiros governos do Estado republicano, havia um discurso que elevava o magistério como "apostolado e sacerdócio" (p. 71). Em vista da consolidação do magistério para o público feminino desde o final do

Tangram - Revista de Educação Matemática, Dourados - MS - v.2 n. 1, pp. 39 - 57 (2018) 


\section{Economia doméstica e educação financeira na escola: diferenças a partir do gênero}

século XIX, devida à maior demanda pela educação popular e aos salários pouco atrativos para os homens - trabalhar na educação, portanto, tornou-se um campo de atuação profissional para o público feminino da época.

Com todo esse incentivo à mulher para a carreira do magistério, ela se identifica com ele e acredita que é o campo de atuação, por excelência, próprio do público feminino. Esse processo de dominação, para Bourdieu (2002), é reforçado por agentes e instituições que inculcam a maneira de pensar dominante, ou seja, é "produto de um trabalho incessante de reprodução, para o qual contribuem agentes específicos e instituições, famílias, Igreja, Escola, Estado" (p. 45). Realizando assim, o que o autor chama de violência simbólica, que ocorre, principalmente, quando o dominado passa a agir de acordo com o que incorporou do dominante, agindo naturalmente na condição de dominado, ou seja, a forma de ver e de se ver no mundo são vistas pela lente do dominador.

Como vimos na reforma de 1879 - Decreto 7.247 -, os conteúdos de Economia Doméstica entravam no currículo com explícitas diferenças dos conhecimentos geradas pela divisão entre os gêneros. Os meninos recebiam um conteúdo de economia atinente às questões sociais e políticas, enquanto as meninas recebiam um conteúdo voltado para o lar.

Anteriormente, na lei que determinou a criação das Escolas de Primeiras Letras, já se observava a distinção dos conteúdos escolares em decorrência do gênero. Por exemplo, no que diz respeito aos conteúdos de aritmética, eram designadas ao público feminino as quatro operações e excluía-se o ensino de geometria, e, a par disso, acrescentavam-se os conteúdos de Economia Doméstica. Nesse contexto, as meninas eram disciplinadas ao que era próprio do âmbito privado do lar, competindo a elas a tarefa de gerir as finanças domésticas. Elas não eram educadas para exercer profissões na esfera pública, sendo essas tipicamente canalizadas ao público masculino.

De acordo com Bourdieu (2002, p. 10), a escola é um lugar de "elaboração e de imposição de princípios de dominação", ratificando o papel de dominante assumido pelos homens e de dominada assumido pelas mulheres. Nesse sentido, o autor pondera que, na divisão social do trabalho, as atividades de vertente pública são voltadas para os homens como atividades descontínuas e extraordinárias, enquanto as atividades privadas são delegadas às mulheres, apresentando-se como rotineiras, contínuas e secretas. Essa divisão se vê expostas nas leis, decretos e decretos-leis de forma explícita, os quais prescreviam disciplinas diferenciadas aos meninos ou às meninas. No parecer desse autor, as mulheres

Tangram - Revista de Educação Matemática, Dourados - MS - v.2 n. 1, pp. 39 - 57 (2018) 


\section{Economia doméstica e educação financeira na escola: diferenças a partir do gênero}

“encarregadas das preocupações vulgares da gestão quotidiana da Economia Doméstica, parecem comprazer-se com as mesquinharias do cálculo, das contas e dos ganhos que o homem de honra deve ignorar" (Bourdieu, 2002, p. 41).

A escola, em sua maioria, transmite valores notadamente patriarcais e presume diferenças entre disciplinas e aptidões masculinas ou femininas, orientando os meninos às carreiras científicas e às meninas as carreiras correlatas ao trabalho doméstico, privado. Todo esse trabalho de inculcação tem sua justificação no fato de as mulheres serem mais inclinadas a assumir o papel de educadoras, de instrução das crianças. Essa função é vista como próxima do perfil da mulher que conduz o marido e os filhos em todas as obrigações domésticas, sendo assim, a escola "contribui para traçar não só os destinos sociais como também a intimidade das imagens de si mesmo" (Bourdieu, 2002, p. 103).

A presença da disciplina de Economia Doméstica nos currículos da escola na época do Império - Lei de 1827 e Decreto de 1879 - esteve proposta nos livros Noções de Vida Doméstica e Noções da Vida Prática do autor Felix Ferreira, que foi adotado para as escolas públicas primárias do Município da Côrte no ano de 1880, com autorização do Conselho Diretor da Instrução Primária e Secundária (Bastos e Garcia, 1999).

A obra Noções de Vida Doméstica traz a disciplina de Economia Doméstica e sua definição. No livro a disciplina era

\footnotetext{
entendida como uma ciência, que toda mulher, qualquer que seja a condição e fortuna, deve conhecer, estudando-a com maior aplicação; (...) arte de dirigir e regular economicamente coisas de casa; arte de bem empregar o tempo, a inteligência e o dinheiro (Bastos e Garcia, 1999, p. 87).
}

No entender das autoras, esse livro é visto como "discurso fundador da disciplina economia doméstica na escola brasileira" (Bastos e Garcia, 1999, p. 92, grifos das autoras). A obra ilustra bem o papel da educação das mulheres, no qual o investimento da escola era a formação de boas donas de casa. Nessa educação incluía-se a boa administração das finanças domésticas, tais como, por exemplo, orçamento e decisões de compras, em que havia o discurso de privilegiar artigos considerados úteis evitando compras desnecessárias e, por consequência, descontrole nas finanças.

A Economia Doméstica era conduzida de forma muito significativa para a educação das mulheres. De forma análoga, dizia-se à época que a disciplina de Economia Doméstica era tão importante para o "governo da família", assim como a economia política era para o

Tangram - Revista de Educação Matemática, Dourados - MS - v.2 n. 1, pp. 39 - 57 (2018) 


\section{Economia doméstica e educação financeira na escola: diferenças a partir do gênero}

"governo da Nação". O livro discorre sobre noções vinculadas à racionalização do uso do tempo, visto como "condição básica para o progresso da família". Aparece também o tema previdência como um conhecimento afim ao necessário aprendizado da gerência correta de uma casa com vistas ao futuro, entendendo como importante o "hábito de observação e de reflexão para 'comprar com prudência e circumspecção para poder comprar bem"” (Bastos e Garcia, 1999, p. 88-89).

Quando o livro pensa a questão da profissionalização do público feminino, são citados alguns trabalhos circunscritos à agricultura, bem como "na indústria, nas belas artes e no ensino", dando a esse último uma ênfase maior, pois o magistério era visto como um ambiente favorável para a mulher. Nessa profissão, a mulher poderia ser a mãe, a dona de casa e a instrutora, ou seja, ter uma missão de grande "alcance moral". Enfatiza ainda que a discussão sobre o mundo do trabalho é um assunto pertinente às mulheres "de classe popular", que "deviam ser preparadas para melhor servir à sociedade" (Bastos e Garcia, 1999, p. 89-90). Às mulheres que possuíam fortuna, a recomendação eram atividades de filantropia.

Para ampliar a discussão sobre a disciplina de Economia Doméstica para as mulheres, o livro fala sobre uma educação "utilitária da mulher" em que temas relacionados ao uso do dinheiro, "ao orçamento da receita e da despesa - governo da casa do ponto de vista econômico", levantam questões concernentes às despesas tomadas como necessárias, ou inúteis, isto é, a boa dona de casa era vista como sinônimo de uma mulher econômica e que, com atitudes como tais, contribuiria para o enriquecimento da família. Acrescenta-se ainda a

perspectiva de condenação do luxo, das despesas com ostentação, das fortunas rapidamente dilapidadas, das manias dispendiosas, do hábito das loterias no Brasil. O texto destaca a mulher que vive para o lar, condenando a mulher que vive para a sociedade, considerada dissipadora de fortunas (Bastos e Garcia, 1999, p. 91).

Todo esse conteúdo explicitado vai ao encontro dos registros que temos sobre o currículo da escola planejado para o público feminino no Brasil antes mesmo da tradução dessa obra e da sua divulgação no país. Conforme as leis publicadas desde o século XIX em âmbito nacional, o conteúdo da esfera doméstica era destinado especificamente às meninas. $\mathrm{O}$ orçamento doméstico como função a ser exercida pela mulher revela a tendência da educação escolar em conservar uma visão e divisão do mundo segundo critérios vinculados

Tangram - Revista de Educação Matemática, Dourados - MS - v.2 n. 1, pp. 39 - 57 (2018) 


\title{
Economia doméstica e educação financeira na escola: diferenças a partir do gênero
}

ao gênero. A discussão de Bourdieu (2002) na obra A Dominação Masculina nos revela como essa visão de mundo foi construída socialmente e acabou por ser inculcada nos homens e mulheres como naturais, e não sociais. O papel da mulher, enaltecido como de extrema importância e nobreza, incutiu no público feminino o papel que este deveria cumprir como mulher e, em ambos, a aceitação do que cada um deveria exercer por si mesmos.

Com a proposta atual de Educação Financeira para a escola básica do Brasil, podemos assinalar que nem tudo é diferente quando se trata da Economia Doméstica, os avanços na educação parecem ainda propor essa visão e divisão do mundo acarretada pelos gêneros - pelo menos nas questões típicas do universo financeiro.

\section{A proposta da estratégia nacional de Educação Financeira}

Em tempos atuais, podemos notar grandes conquistas do público feminino quanto às oportunidades no mercado de trabalho. Contudo, o modo de divisão nas atividades exercidas por elas ainda permanece. Na teorização de Bourdieu (2002), mesmo com a chegada da mulher ao espaço público, a lógica de atuação continua inspirada pela diferença entre os gêneros. O espaço público legitima funções que são definidas como tipicamente masculinas e funções, socialmente arquitetadas para o público feminino. Para o autor,

\begin{abstract}
as próprias mudanças da condição feminina obedecem sempre à lógica do modelo tradicional entre o masculino e o feminino. Os homens continuam a dominar o espaço público e a área de poder (sobretudo econômico, sobre a produção), ao passo que as mulheres ficam destinadas (predominantemente) ao espaço privado (doméstico, lugar da reprodução) em que se perpetua a lógica da economia de bens simbólicos, ou a essas espécies de extensões deste espaço, que são os serviços sociais (sobretudo hospitalares) e educativos, ou ainda aos universos da produção simbólica (áreas literária e artística, jornalismo etc.) (Bourdieu, 2002, p. 111).
\end{abstract}

Nesta seção, analisaremos duas imagens que estão no site de divulgação da Enef. Essa Estratégia tem o propósito de trabalhar a Educação Financeira com vários grupos da sociedade, incluindo as crianças e jovens da escola básica. Em seu artigo $1^{\circ}$ do Decreto 7.397/2010 institui que sua finalidade é "promover a educação financeira e previdenciária" (BRASIL, 2010). Nas imagens, o que nos chamou a atenção foram os diferentes papéis do homem e da mulher, os quais nos permitem interpretações sobre como cada gênero pode participar das ações alusivas à Educação Financeira.

Tangram - Revista de Educação Matemática, Dourados - MS - v.2 n. 1, pp. 39 - 57 (2018) 


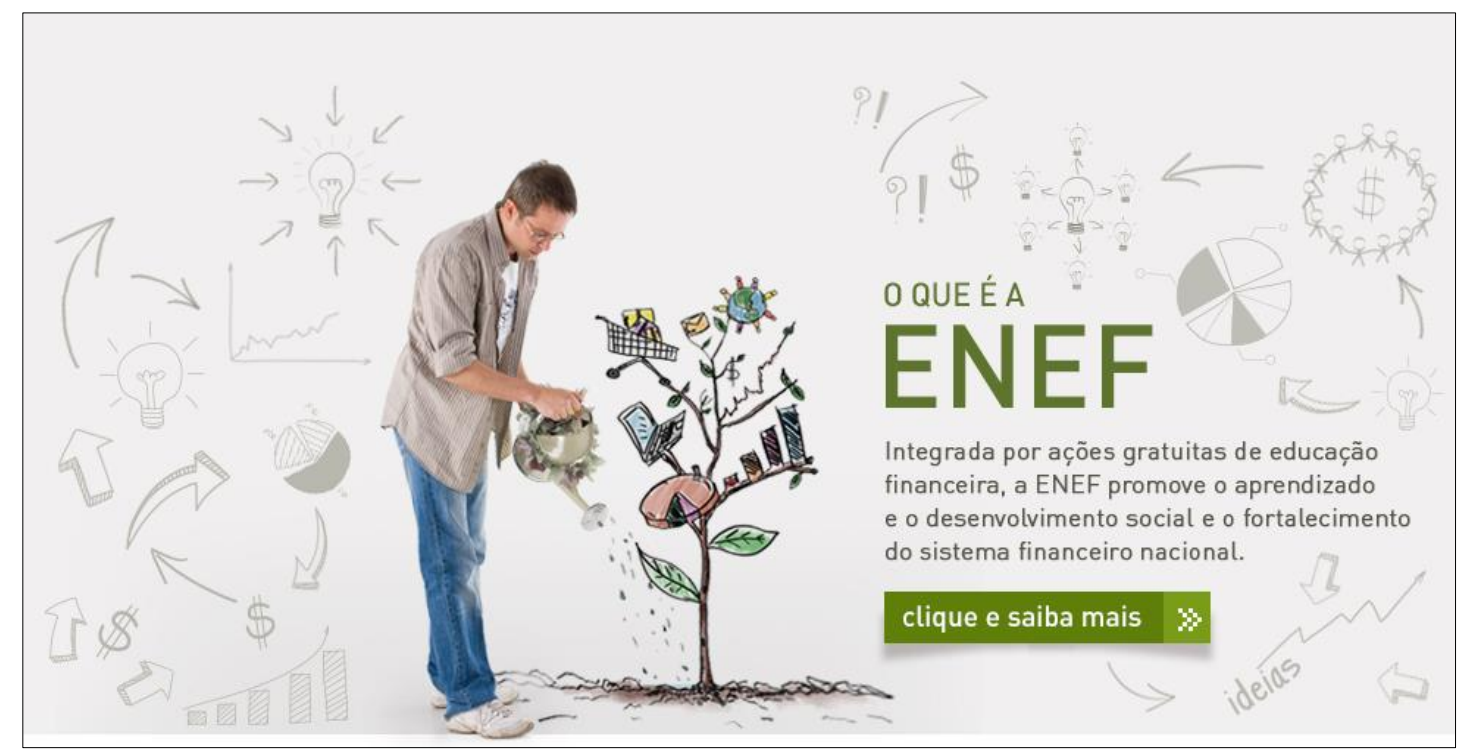

Figura 1: Imagem de divulgação da ENEF.

Fonte: <http://www.vidaedinheiro.gov.br/index.php>. Acesso em: 13 out. 2016.

Dos desenhos espalhados na figura, podemos observar:

- $\quad$ diversos tipos de gráficos estatísticos (colunas, pizza);

- $\quad$ setas em várias direções;

- lâmpadas representando as novas ideias;

- $\quad$ um regador cheio de notas - de dinheiro?;

- nos galhos da árvore temos: gráficos, carrinhos de compras, globo terrestre, livro aberto;

- $\quad$ um homem que aparenta idade entre 30 e 50 anos, regando a árvore;

- $\quad$ um texto: O que é a Enef. Integrada por ações gratuitas de educação financeira, a Enef promove o aprendizado e o desenvolvimento social e o fortalecimento do sistema financeiro nacional - referindo-se a ícones de navegação do site.

$\mathrm{Na}$ figura vemos um homem em uma situação de cuidado com uma árvore. No meio ambiente, com o ato de cuidar corretamente das plantas, regando-as e fornecendo-lhes condições favoráveis de sobrevivência, garantimos-lhes um retorno satisfatório, ou seja, elas florescerão. De forma análoga, a propósito da árvore regada pelo homem da imagem, em cujos galhos estão diversos objetos denotando investimentos, podemos interpretar que, no meio financeiro, tudo decorre, então, como se o cuidado e atenção com as finanças e investimentos, garantissem também resultados positivos. Esse universo de investimentos seria permeado por análises estatísticas, ideias, direções e decisões.

Tangram - Revista de Educação Matemática, Dourados - MS - v.2 n. 1, pp. 39 - 57 (2018) 


\section{Economia doméstica e educação financeira na escola: diferenças a partir do gênero}

$\mathrm{Na}$ seção anterior, quando tratamos das leis tangentes aos currículos anteriores da escola brasileira, aos meninos era direcionada uma disciplina chamada de "economia social" (Decreto de 1879), que, em nossa interpretação, estaria conectada às ações figuradas na imagem de divulgação da ENEF. Nesse sentido, o homem é impelido às atividades da esfera pública e ao mercado de trabalho. É como se, a eles, fosse reservado um futuro associado ao mundo dos negócios, dos investimentos e acumulação de riquezas.

A próxima imagem nos mostra uma representação diferente.

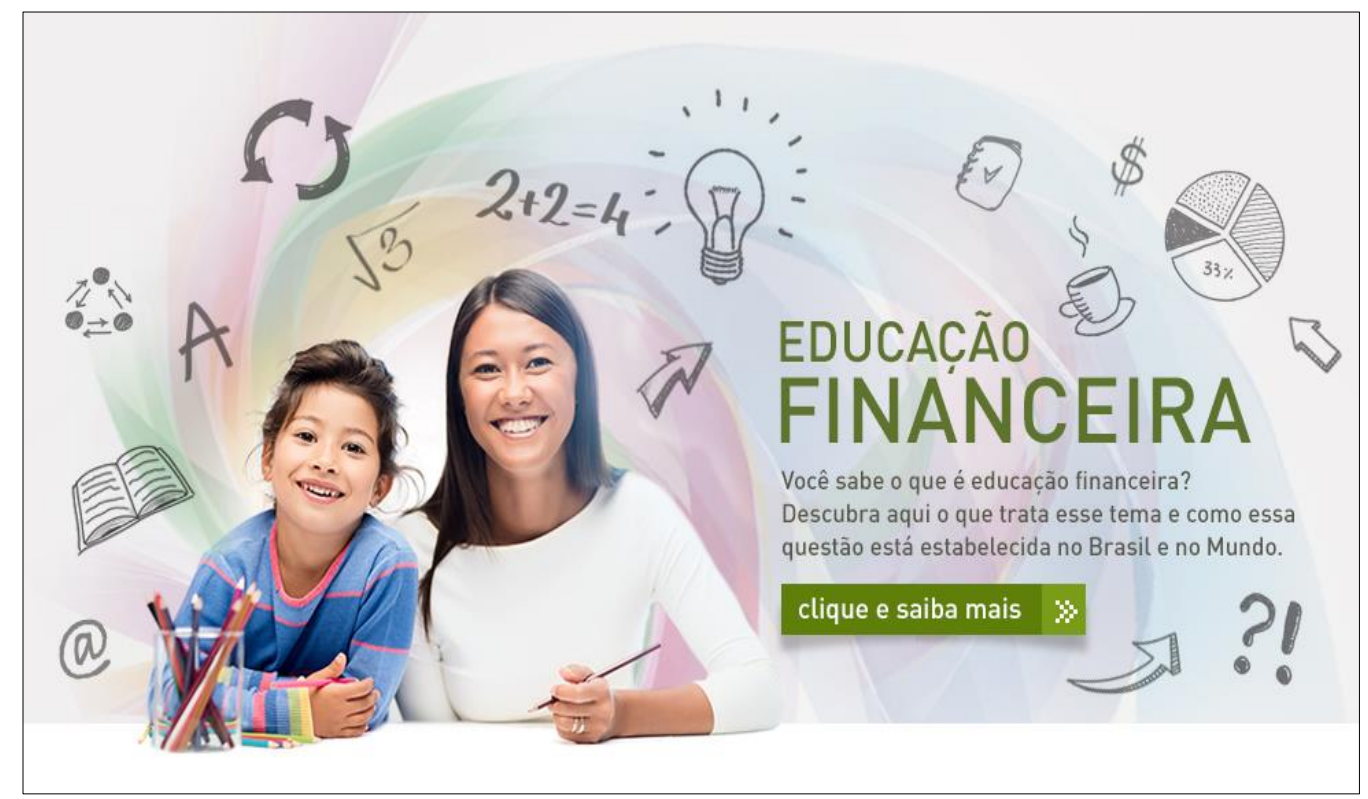

Figura 2: Imagem de divulgação da Enef.

Fonte: <http://www.vidaedinheiro.gov.br/index.php>. Acesso em: 13 out. 2016.

A representação dessa segunda imagem pode-nos remeter à doxa de que os conhecimentos afins ao mundo financeiro devem ser ensinados às crianças e, ainda, uma visão do mundo social e do lugar que cabe à mulher, colocando-a "no prolongamento das funções domésticas", como, por exemplo, educar os filhos/as crianças (Bourdieu, 2002, p. 111). Nesse caso, tudo se passa, então, como se o papel das mulheres no meio financeiro fosse o de ensinar as crianças.

Os inúmeros desenhos no fundo da imagem representam os conhecimentos, disciplinares ou não, que parecem compor a Educação Financeira, como podemos observar:

- livro;

- $\quad$ o símbolo @ - que pode representar os meios eletrônicos de pesquisa;

- $\quad$ cálculos matemáticos;

Tangram - Revista de Educação Matemática, Dourados - MS - v.2 n. 1, pp. 39 - 57 (2018) 


\section{Economia doméstica e educação financeira na escola: diferenças a partir do gênero}

- $\quad$ setas em várias direções;

- lâmpada representando ideias;

- $\quad$ gráficos;

- $\quad$ pontos de interrogação e exclamação;

- $\quad$ uma xícara - de café?;

- $\quad$ uma mulher - parece estar de aliança (casada?);

- uma criança;

- $\quad$ uma mesa com porta-lápis, com vários lápis;

- um texto: Educação Financeira. Você sabe o que é educação financeira? Descubra aqui o que trata esse tema e como essa questão está estabelecida no Brasil e no Mundo -referindo-se a ícones de navegação do site.

Para a Enef, o trabalho com essa temática na sala de aula pode ser visto como um meio de reforçar o ensino das disciplinas de Matemática e Língua Portuguesa. Essas orientações estão incluídas nos materiais didáticos publicados pelo Conef (2014). De acordo com Hofmann e Moro (2012), o nexo entre Educação Matemática e Educação Financeira pode ser produtivo pois, para as autoras, a Educação Financeira é uma forma "relevante no desenvolvimento de competências matemáticas aplicadas às práticas corriqueiras dos alunos, as de natureza financeira e econômica" (p. 52). Dessarte, os desenhos delineados na imagem anterior parecem fortalecer essa interlocução entre o mundo financeiro, o cotidiano e as disciplinas escolares.

Essas duas imagens de divulgação da Enef parecem carregar princípios análogos aos que estavam presentes nos documentos dos séculos XIX e XX, indicados na seção anterior. Por um lado, era a economia social para os meninos e, por outro, as noções de Economia Doméstica para o público feminino. Para Bourdieu (2002), as divisões entre os gêneros permaneceram mesmo quando a mulher passa a desenvolver atividades na esfera pública. Às mulheres cabe o ofício de ensinar as crianças e, aos homens, investir para acumular riquezas.

No modo como interpretamos essas imagens, por um viés sociológico, a Educação Financeira, quando elaborada e divulgada pela ENEF dessa forma, acaba por legitimar um tipo de Educação Financeira. Essa figuração satisfaz os grupos que produziram os materiais de divulgação que, nesse sentido, acabam por produzir um doxa sobre o assunto.

Tangram - Revista de Educação Matemática, Dourados - MS - v.2 n. 1, pp. 39 - 57 (2018) 


\section{Economia doméstica e educação financeira na escola: diferenças a partir do gênero}

De acordo com Bourdieu (1996), doxa é como um "senso comum naturalizado", e, por isso, não a vê como uma construção social, mas sim como algo natural, que passa a ser vivido sem questionamentos. Nesse aspecto, doxa é vista como um "ponto de vista particular, o ponto de vista dos dominantes, que se apresenta e se impõe como ponto de vista universal” (BOURDIEU, 1996, p. 120).

\section{Considerações finais}

Neste artigo, nosso objetivo foi discutir, por um viés sociológico, os conteúdos alusivos às finanças na sala de aula, considerando a presença no currículo da escola da disciplina de Economia Doméstica e a Educação Financeira proposta pela Enef. Na análise, salientamos prioritariamente as diferenças fundadas em relação ao gênero, que mostraram perdurar no tempo: assim como interpretamos, às meninas ficou reservado uma sintonia com a esfera privada ou de ensino e, aos meninos, uma educação voltada para o mundo externo.

A escola, como desvelada por Bourdieu (2015), fornece indicações, percursos e, ainda, "métodos e programas de pensamento" (p. 214). Sendo assim, entendemos que o currículo quando proposto e desenvolvido na escola, tende a naturalizar uma forma de pensamento, no nosso caso sobre as finanças, que coloca os meninos e as meninas em papéis diferentes na sociedade capitalista. Para Nogueira e Nogueira (2002), os estudos de Bourdieu nos ajuda a entender as conexões entre "o sistema de ensino e a estrutura social" (p. 35), ou seja, ao estudarmos as disciplinas que abordam as finanças na sala de aula auferimos subsídios para entender a forma como a sociedade propõe o intercâmbio entre esses saberes.

Em nossa compreensão, a disciplina de Economia Doméstica - agora ausente dos currículos da escola no Brasil - e a atual Educação Financeira, embora permaneçam as discussões sobre as finanças de um modo geral, elas se distanciaram quanto à ênfase dada em cada uma. Além do questionamento do gênero, destaca-se a dimensão considerada em cada uma. No caso da Economia Doméstica, o foco estava nas dimensões da família, do lar. A atenção estava na boa administração da casa - que deveria ser exercida pela mulher articulando o orçamento familiar, o controle dos gastos, a organização e a limpeza. A Educação Financeira, que está sendo proposta para a escola por meio da Enef e que consta como um dos contextos que devem ser abordados na sala de aula - BNCC - (Brasil, 2018), focaliza a dimensão individual. Por essa Educação Financeira, tudo se dá como se o

Tangram - Revista de Educação Matemática, Dourados - MS - v.2 n. 1, pp. 39 - 57 (2018) 


\section{Economia doméstica e educação financeira na escola: diferenças a partir do gênero}

indivíduo é quem devesse primeiro cultivar hábitos saudáveis nas finanças, para depois expandir esses conhecimentos para a esfera familiar. Para o discurso de implantação da Educação Financeira na escola, um indivíduo educado financeiramente reflete em uma sociedade igualmente educada.

Com essa mudança de foco, o agente principal vem a ser o indivíduo, ou seja, conhecimentos que envolviam a esfera familiar agora devem ser tratados na esfera individual. Orçamento, decisões de compras, planejamento para o futuro, tudo deverá ser considerado na perspectiva do individual.

Não podemos deixar de sublinhar também os diferentes alcances no país sobre o currículo e a proposta de trabalho com as finanças na sala de aula. Nos séculos anteriores, cultivava-se uma escola mais restrita, reservada a uma pequena parte da população. Com a expansão da escolaridade básica, em que a maioria da população tem acesso, as propostas feitas à escola básica alcançaram uma abrangência maior. A proposta de Educação Financeira, pensada por meio da Enef, está disponível para todo o território nacional (todos os materiais produzidos estão disponíveis no site de divulgação); dessa forma, qualquer escola hoje tem acesso e pode trabalhar com a temática na sala de aula.

Por meio desses documentos examinados, compreendemos as doxas que são infundidas pelo Estado por meio de suas políticas públicas e materiais de ampla divulgação destinados à escola básica. Para Bourdieu (2014), doxa é a representação de "um ponto de vista particular" (p. 238), podendo o Estado ser definido como "um princípio de ortodoxia" (p. 30). Sendo assim, o Estado se posiciona como "produtor de princípios de classificação, isto é, de estruturas estruturantes capazes de serem aplicadas a todas as coisas do mundo, e em especial às coisas sociais" (p. 227). Dessarte, os documentos elaborados para a escola, tanto os decretos e decretos-lei dos séculos anteriores e o decreto mais atual da Enef, são gerados por políticas educacionais que buscam introduzir no espaço escolar um conjunto de disciplinas e/ou conteúdos que julgam necessários à educação das crianças e adolescentes. No caso que apresentamos, são exemplos a disciplina de Economia Doméstica e a Educação Financeira, reservadas as interpretações já explanadas neste artigo. Ademais, revelamos tanto os assuntos da Economia Doméstica como os da Educação Financeira produzidos pela Enef como doxas impostas desde o ponto de vista dos seus produtores.

Essas mudanças que frisamos sobre os tópicos das finanças no ambiente escolar estão diretamente associados, em nosso modo de ver, com a sociedade e a época correspondente.

Tangram - Revista de Educação Matemática, Dourados - MS - v.2 n. 1, pp. 39 - 57 (2018) 


\section{Economia doméstica e educação financeira na escola: diferenças a partir do gênero}

Por meio da análise sociológica, concluímos que tanto a Economia Doméstica quanto a Educação Financeira atual são resultados de uma construção social. Atualmente, a temática está vinculada aos preceitos do capitalismo financeiro e ao neoliberalismo. Os autores Dardot e Laval (2016) defendem a tese de que o neoliberalismo é "fundamentalmente uma racionalidade, e como tal, tende a estruturar e organizar não apenas a ação dos governantes, mas até a própria conduta dos governados" (grifos dos autores, p. 17).

Para autores da Sociologia Econômica, há a construção social de um homo economicus (Jardim, 2015, p. 12), que está atrelado ao indivíduo com o fim de maximizar os lucros. Segundo Boltanski e Chiapello (2009), é típico perfil do capitalista que busca recrudescer os recursos mediante investimentos.

Pela análise empreendida, esse perfil esteve restrito ao público masculino, tanto por meio da disciplina de economia social (Decreto de 1879) tanto pela proposta de Educação Financeira (divulgada pela Enef). Por outra vertente, as propostas da ENEF revelaram que a doxa incutida pelo Estado e que pode ser legitimada na escola, acaba por sedimentar o discurso de uma postura individualista na sociedade. Nessa ótica, a escola é considerada um espaço que subsidia a formação de ideias e disposições nos estudantes. Dessarte, ser educado financeiramente promoveria sucesso financeiro, que estaria impelindo à acumulação de riquezas e ao investimento e ainda, por sua vez, a formação desse homo economicus estaria reservada aos homens na esfera pública.

Ademais, em concordância com Bourdieu (1996, 2002), percebemos que as diferenças ratificadas na escola sobre a atuação do homem e da mulher na vida em sociedade, particularmente em assuntos afetos à realidade financeira, naturalizam seus modos de verem e de se verem no mundo por meio da doxa dominante inculcada nesse espaço.

O presente trabalho foi realizado com apoio da Coordenação de Aperfeiçoamento de Pessoal de Nível Superior - Brasil (CAPES) - Código de Financiamento 001.

\section{Referências bibliográficas}

Almeida, J. S. (2006). Vestígios para uma reinterpretação do magistério feminino em Portugal e no Brasil a partir do século XIX. In: D. (. Saviani, O legado educacional do século XIX. Campinas, SP: Autores Associados.

Bastos, M. C., \& Garcia, T. M. (1999). Leituras de Formação - Noções de Vida Doméstica (1879): Félix Ferreira traduzindo Madame Hippeau para a Educação das mulheres brasileiras. Revista História da Educação, 77-92.

Boltanski, L., \& Chiapello, È. (2009). O Novo Espírito do Capitalismo. São Paulo: Editora WMF Martins Fontes.

Tangram - Revista de Educação Matemática, Dourados - MS - v.2 n. 1, pp. 39 - 57 (2018) 
Bourdieu, P. (1996). Razões Práticas: sobre a teoria da ação. Campinas, SP: Papirus.

Bourdieu, P. (2002). A Dominação Masculina. Rio de Janeiro: Bertrand Brasil.

Bourdieu, P. (2014). Sobre o Estado. São Paulo: Companhia das Letras.

Bourdieu, P. (2015). Sistemas de Ensino e Sistemas de Pensamento. In: S. Miceli, A Economia das Trocas Simbólicas (pp. 203-229). São Paulo: Perspectiva.

Brasil. (2010). Estratégia Nacional de Educação Financeira. Fonte: Planalto - Brasília: http://www.planalto.gov.br/ccivil_03/_Ato2007-2010/2010/Decreto/D7397.htm

Brasil. (2018). Base Nacional Comum Curricular. Fonte: Ministério da Educação - Brasília: http://basenacionalcomum.mec.gov.br/wpcontent/uploads/2018/04/BNCC_19mar2018_versaofinal.pdf

Conef. (2014). Educação Financeira nas escolas: ensino fundamental. Livro do professor. Brasília: CONEF.

Dardot, P., \& Laval, C. (2016). A nova razão do mundo: ensaio sobre a sociedade neoliberal. São Paulo: Boitempo.

Farias, J. V. (2017). O Profmat e as relações distintivas no campo da matemática. Tese (Doutorado em Educação) - Centro de Educação e Ciências Humanas. São Carlos: Universidade Federal de São Carlos.

Fernandes, L. (2014). Cenários do ensino de matemática em escolas rurais da cidade de Tanabi, SP. Campinas: Dissertação (Mestrado em Educação) - Faculdade de Educação, Universidade Estadual de Campinas.

Fiorentini, D., \& Lorenzato, S. (2007). Investigação em Educação Matemática: percursos teóricos e metodológicos. Campinas: Autores Associados.

Hofmann, R. M., \& Moro, M. L. (jul/dez de 2012). Educação matemática e educação financeira: perspectivas para a ENEF. Zetetiké - FE/Unicamp, pp. 37-54.

Jardim, M. C. (2015). Nem Sagrado, nem Profano: MercadoS como Fato Social Total. In: M. C. JARDIM, MercadoS: nem Sagrado, nem Profano (pp. 7-18). São Paulo: Cultura Acadêmica.

Nogueira C. M. M. e Nogueira, M. A. (2002). A Sociologia da Educação de Pierre Bourdieu: limites e contribuições. Educação \& Sociedade, 15-36.

Romanelli, O. O. (1978). História da Educação no Brasil. Petrópolis, RJ: Vozes.

Saviani, D. (2008). História das ideias pedagógicas no Brasil. Campinas, SP: Autores Associados.

Serrano, I. A. (1954). Noções de Economia Doméstica. São Paulo: Companhia Editora Nacional.

Souza, R. F. (2006). Espaço da Educação e da Civilização: origens dos Grupos Escolares no Brasil. In: D. (. Saviani, O legado educacional do século XIX (pp. 33-84). Campinas, SP: Autores Associados.

Vilela, D. S., \& Souza Neto, J. A. (2012). Práticas de avaliação e capital simbólico da Matemática: o caso da Obmep. Rematec, 62-82.

Enviado:30/09/2018

Aceito: $10 / 11 / 2018$

Tangram - Revista de Educação Matemática, Dourados - MS - v.2 n. 1, pp. 39 - 57 (2018) 